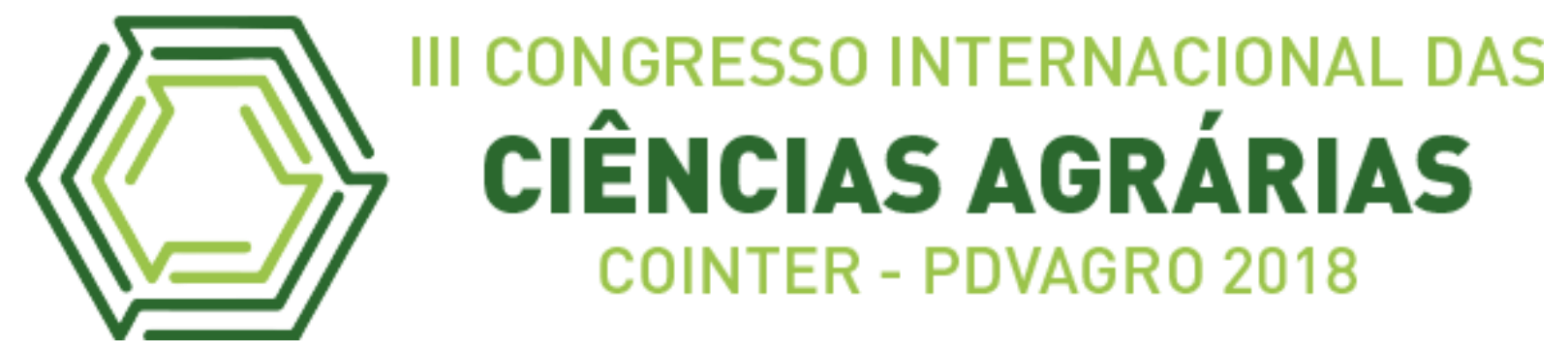

\title{
CONSTRUÇÃO DE CONHECIMENTO: DIA DE CAMPO NO ASSENTAMENTO LUIZA FERREIRA
}

\section{KNOWLEDGE CONSTRUCTION: FIELD DAY IN THE SETTLEMENT LUIZA FERREIRA}

\author{
Apresentação: Relato de Experiência \\ José Marques dos Santos ${ }^{1}$; Maciel Alves Tavares²; Elias Inácio da Silva ${ }^{3}$ \\ DOI: https://doi.org/10.31692/2526-7701.IIICOINTERPDVAGRO.2018.00722
}

\section{Introdução}

As atividades de Extensão Rural buscam diminuir a distância entre os centros acadêmicos e as comunidades rurais através da troca e construção de conhecimentos, buscando assim, difundir o conhecimento produzido dentro das instituições de ensino, pesquisa, extensão e inovação e estimular a adoção de novas práticas e tecnologias sustentáveis de forma que possam auxiliar no desenvolvimento rural, fazendo com que os agricultores possam produzir de forma sustentável, com qualidade, em quantidade e sem degradar o ambiente.

O presente trabalho tem por objetivo expor a experiência vivenciada por estudantes do Bacharelado em Agronomia do IFPE Campus Vitória de Santo Antão em um dia de campo realizado no Assentamento Luiza Ferreira, localizado na Zona Rural de Moreno - PE.

\section{Relato de Experiência}

Participando das atividades da semana nacional de ciência e tecnologia, e com o intuito de levar até as comunidades circunvizinhas do Campus a divulgação de técnicas adequadas de manejo do solo e armazenamento de sementes, bem como, construir conhecimentos através do diálogo com os moradores locais, no dia 25 de outubro de 2018 estudantes do Bacharelado em Agronomia e também estudantes do curso técnico em Agropecuária do IFPE campus Vitória de Santo Antão, instruídos pelos Professores José Carlos da Costa e Denise de Santana Silva, se deslocaram até o assentamento de reforma

\footnotetext{
${ }^{1}$ Bacharelado em Agronomia, IFPE, josemarquesdossantos87@gmail.com

2 Bacharelado em Agronomia, IFPE, macieltavares15@gmail.com

${ }^{3}$ Professor Doutor de Agronomia, IFPE, elinasi.silva@gmail.com
} 
agrária Luiza Ferreira que fica localizado na Zona Rural do Município de Moreno - PE para a realização de um dia de campo com os agricultores que lá são assentados.

“A extensão rural contemporânea tem como desafio desenvolver um processo metodológico participativo que seja capaz de atender os desafios do desenvolvimento rural sustentável, nas suas diversas dimensões." (RAMOS; SILVA; BARROS, 2013, p. 8). Sabendo disso, os estudantes do Bacharelado em Agronomia realizaram três atividades participativas com os agricultores, que foram: como construir curvas de nível e sua importância para as atividades agrícolas, como realizar coleta de solo para enviar para análise e formas adequadas de armazenamento de sementes.

Tais atividades foram realizadas através de demonstrações práticas com a participação dos agricultores e tiveram por finalidade demonstrar para estes a existência de tecnologias simples, porém eficientes, que eles devem adotar em suas atividades agrícolas para conseguir realizar um manejo conservacionista do solo mantendo sua fertilidade e também para armazenar suas sementes crioulas de forma segura e por um maior período de tempo.

Este dia de campo foi uma experiência enriquecedora para todos, pois proporcionou, através das atividades realizadas, a troca e construção de conhecimentos fortalecendo nos estudantes o aprendizado adquirido em sala de aula e levando para os agricultores um pouco do conhecimento produzido dentro das academias. Desse modo, criou uma ligação que torna possível a realização de outras futuras atividades que venham juntar novamente comunidade acadêmica e agricultores em um momento de troca de saberes e construção de conhecimentos.

Imagem 1: Marcação de curvas de nível. Fonte: Própria

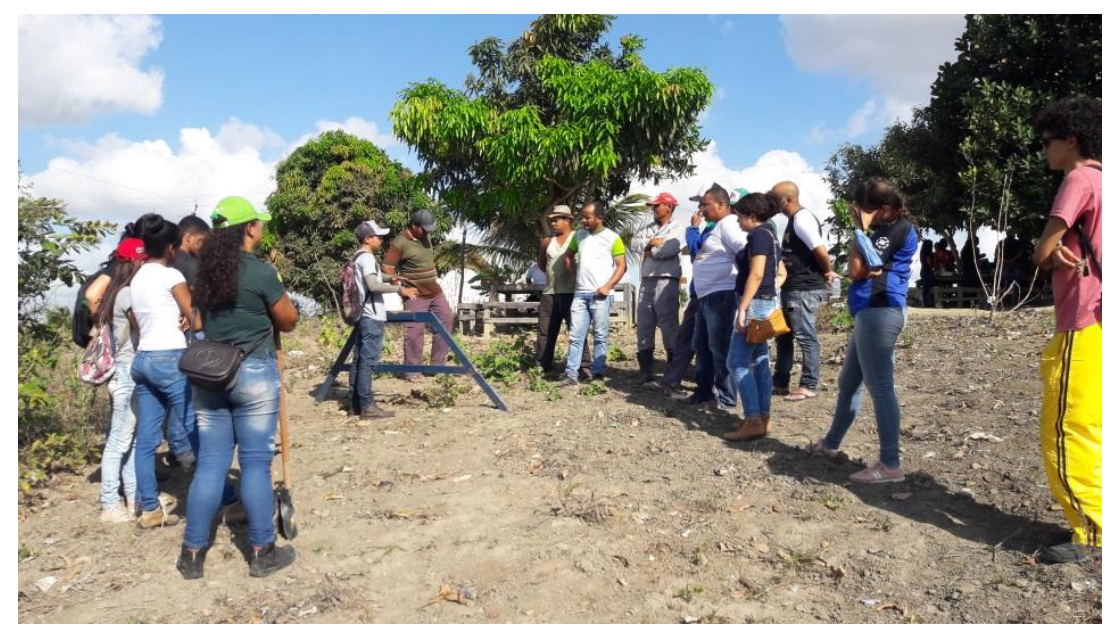

\section{Considerações}


É através da extensão Rural que as instituições de ensino, pesquisa, extensão e inovação dialogam com as comunidades rurais. Porém, apesar da importância que a Extensão Rural tem para o desenvolvimento rural do Brasil, pouco se investe nesse setor. Com isso, importantes trabalhos de pesquisa são desenvolvidos, mas seus resultados não chegam até aqueles que mais precisam desses resultados, que são os agricultores.

O conhecimento não foi feito para ser guardado e sim para ser difundido com aqueles que o irão colocar em prática. Daí a importância da realização deste dia de campo, para unir o conhecimento acadêmico com o conhecimento prático, buscando o desenvolvimento sustentável da agricultura e a permanência do homem no campo.

\section{Referências}

RAMOS, Giuberto de Lima; SILVA, Ana Paula Gomes da; BARROS, Antônio Alves da Fonseca. Manual de metodologia de extensão rural. Recife: Instituto Agronômico de Pernambuco - IPA, 2013. 58p. 